\title{
MODIFICAÇÕES TEXTURAIS DE TOMATES HETEROZIGOTOS NO LOCO ALCOBAÇA ${ }^{1}$
}

\author{
EDUARDO VALÉRIO DE BARROS VILAS BOAS² ${ }^{2}$ ADIMILSON BOSCO CHITARRA ${ }^{3}$, \\ WILSON ROBERTO MALUF ${ }^{4}$ e MARIA ISABEL FERNANDES CHITARRA ${ }^{5}$
}

\begin{abstract}
RESUMO - Foram avaliadas as modificações ocorridas durante o amadurecimento de três pares de híbridos de tomates do grupo multilocular, quase isogênicos, à exceção do loco alcobaça. O experimento foi conduzido na Universidade Federal de Lavras, em delineamento em blocos casualizados. Os pares de híbridos (Stevens x Flora Dade e Stevens x TOM-559; Piedmont x Flora Dade e Piedmont x TOM-559; NC-8276 x Flora Dade e NC-8276 x TOM-559) foram avaliados em quatro estádios de amadurecimento (breaker, rosa, vermelho-claro e vermelho), em quatro repetições. Os híbridos cujo genitor comum foi Flora Dade corresponderam ao genótipo normal $(+/+)$, enquanto os híbridos heterozigotos alcobaça $(+/ a l c)$ foram provenientes do genitor comum TOM-559. A textura não foi afetada pelo alelo alcobaça nos estádios predeterminados de amadurecimento. Já a porcentagem de solubilização das substâncias pécticas, bem como a atividade das enzimas pectinametilesterase e poligalacturonase, foram influenciadas pelo alelo alcobaça, que determinou a sua contenção. O amadurecimento dos tomates $(+/+) \mathrm{e}(+/$ alc $)$ foi marcado por intenso amaciamento, acompanhado por incremento na atividade da poligalacturonase e solubilização das substâncias pécticas.
\end{abstract}

Termos para indexação: Lycopersicon esculentum, métodos de melhoramento, atividade enzimática, pectinas, solubilização, amadurecimento, manutenção de qualidade.

\section{TEXTURAL CHANGES OF HETEROZYGOUS TOMATOES IN THE $A L C O B A C A$ LOCI}

ABSTRACT - Textural changes occurred during ripening of three pairs of plurilocular tomato's hybrids, nearing isogenics, excepting the alcobaca loci, were studied. The trial was carried out in Universidade Federal de Lavras (UFLA), MG, Brazil, with a randomized complete block design. The pairs of hybrids (Stevens x Flora Dade e Stevens x TOM-559; Piedmont x Flora Dade e Piedmont x TOM-559; NC-8276 x Flora Dade e NC-8276 x TOM-559) were evaluated in four stages of ripening (breaker, pink, light-red and red), in four replications. Hybrids whose common genitor was Flora Dade corresponded to the normal genotype $(+/+)$, whereas the alcobaca heterozygous hybrids $(+/ a l c)$ were originated from the common genitor TOM-559. Texture was not affected by the alcobaca allele in the predetermined stages of ripening. On the other hand, the solubilization percentage of pectic substances as well as the activity of pectinmethilesterase and polygalacturonase were influenced by the alcobaca allele which determined its contention. Tomato ripening, $(+/+)$ and $(+/ a l c)$, was characterized by intense softening associated with an increase in polygalacturonase activity and solubilization of pectic substances.

Index terms: Lycopersicon esculentum, breeding methods, enzimic activity, pectins, solubilizing, ripening, keeping quality.

${ }^{1}$ Aceito para publicação em 19 de julho de 1999. Extraído da tese de doutorado do primeiro autor, apresentada à Universidade Federal de Lavras (UFLA), Lavras, MG.

${ }^{2}$ Eng. Agrôn., Dr., Prof. Adjunto, Dep. de Ciências dos Alimentos, UFLA, Caixa Postal 37, CEP 37200-000 Lavras, MG. E-mail: evbvboas@ufla.br

${ }^{3}$ Eng. Agrôn., Ph.D., Prof. Titular, Dep. de Ciências dos Alimentos, UFLA. E-mail: chitarra@ufla.br

${ }^{4}$ Eng. Agrôn., Ph.D., Prof. Titular, Dep. de Agricultura, UFLA. E-mail: wrmaluf@ufla.br

${ }^{5}$ Bioquímico/Farmacêutico, Ph.D., Prof. Titular, Dep. de Ciências dos Alimentos, UFLA. E-mail: chitarra@ufla.br

\section{INTRODUÇÃO}

Após a aparência visual, o mais importante fator na qualidade de tomates é a firmeza, que está intimamente associada com o estádio de amadurecimento. $\mathrm{O}$ amadurecimento dos frutos é um processo complexo que os habilita para o consumo (Lelièvre et al., 1997). Em tomates, como na maioria dos frutos, o amadurecimento é marcado por modificações texturais, associadas ao metabolismo de carboidratos 
da parede celular, que culminam com a redução da sua firmeza (Huber, 1983; Huysamer et al., 1997a, 1997b). A maioria dos consumidores prefere os frutos firmes que não perdem muito suco quando cortados, e que não têm casca dura. A firmeza afeta a suscetibilidade dos tomates a danos físicos, e, conseqüentemente, sua aptidão para comercialização.

As substâncias pécticas constituem a classe de polissacarídeos da parede celular, que sofre a mais marcante modificação durante o amadurecimento dos tomates (Steele et al., 1997). Mudanças em pectinas, associadas ao amadurecimento, têm sido extensivamente documentadas; a solubilização e despolimerização das substâncias pécticas, normalmente, acompanham o amaciamento dos tomates durante 0 seu amadurecimento (Huber, 1983; Brummell \& Labavitch, 1997). Com o amadurecimento, os poliuronídeos da parede celular de tomates aumentam a sua solubilidade em água (Gross \& Wallner, 1979) em resposta à sua despolimerização (Huber, 1983), o que culmina com o amaciamento dos frutos.

A solubilização de substâncias pécticas de tomates tem sido associada à hidrólise mediada pela enzima poligalacturonase (PG) (Huber, 1983; Koch \& Nevins, 1989), enzima esta que catalisa a clivagem hidrolítica de ligações $\alpha-(1 \rightarrow 4)$ galacturonana (Lazan \& Ali, 1993). A extensão da liberação de poliuronídeos por PG parece ser dependente do estádio do desenvolvimento do fruto (Koch \& Nevins, 1989).

As pectinas são secretadas na parede celular sob a forma metil-esterificada, onde são desesterificadas pela pectinametilesterase (PME) e tornam-se disponíveis para ligações cruzadas intermoleculares medidas por $\mathrm{Ca}^{2+}$ (Carpita \& Gibeaut, 1993). A PG é mais ativa na degradação de pectinas desmetiladas que metiladas (Koch \& Nevins, 1989). Portanto, a PME, uma enzima que catalisa a desmetilação do grupo carboxílico $\mathrm{C}_{6}$ de resíduos galacturanosil, pode desempenhar um importante papel na determinação da extensão à qual a pectina é acessível à degradação por PG, estando envolvida no processo de amaciamento (Gaffe et al., 1997). Na verdade, tem sido sugerido que a maior suscetibilidade das paredes celulares de tomates à ação da PG durante o amadurecimento é devida à ação da PME (Koch \& Nevins, 1989).
O mutante de não-amadurecimento alcobaça afeta drasticamente a taxa de amadurecimento dos tomates, dependendo do background genético e maturidade fisiológica no momento da colheita. A capacidade de armazenamento da cultivar Alcobaça é controlada por um único alelo recessivo denominado alc (Mutschler, 1984). Híbridos heterozigotos para o alelo alc não mostram efeitos detrimentais na coloração, firmeza, ou tamanho dos frutos, e podem produzir frutos com aceitação comercial e com conservação pós-colheita significativamente maior (Souza, 1995; Freitas, 1996; Araújo, 1997). O efeito do alelo alcobaça em heterozigose foi observado no retardo e atenuação dos processos de solubilização de pectinas e amaciamento de tomates, relacionado a uma redução nas atividades das enzimas PME e PG (Resende, 1995; Filgueiras, 1996). A atividade da PG é muito baixa nestes mutantes (Hobson \& Grierson, 1993).

Este trabalho teve por objetivo estudar as modificações texturais ocorridas durante o amadurecimento dos tomates e influenciadas pelo alelo alcobaça em heterozigose.

\section{MATERIAL E MÉTODOS}

Foram avaliados três pares de híbridos de primeira geração $\left(\mathrm{F}_{1}\right)$ de tomates do grupo multilocular provenientes de experimento conduzido na Universidade Federal de Lavras. Os híbridos, dentro de cada par, eram isogênicos à exceção do loco alcobaça. Foram utilizados os híbridos obtidos dos seguintes cruzamentos:

$\left[\right.$ Stevens $_{(+/+)} \times$TOM-559(alc/alc $\left.)\right]_{(+/ \text {alc })} \mathrm{e}$

$\left[\text { Stevens }_{(+/+)} \times \text {Flora Dade }_{(+/+)}\right]_{(+/+)}$

$[\text { Piedmont }(+/+) \times \text { TOM-559 } \text { (alc/alc })_{(+/ a l c)} \mathrm{e}$

$\left[\text { Piedmont }_{(+/+)} \times \text {Flora Dade }(+/+)\right]_{(+/+)}$

$\left[\mathrm{NC}-8276_{(+/+)} \times \mathrm{TOM}-559_{(\text {alc/alc })}\right]_{(+/ a l c)} \mathrm{e}$

$\left[\mathrm{NC}-8276_{(+/+)} \text {x Flora Dade }(+/+)\right]_{(+/+)}$

sendo que as notações $(+/+)$ correspondem a frutos de amadurecimento normal; (alc/alc), homozigotos alcobaça; e (+/alc), heterozigotos alcobaça

Os frutos de segundo, terceiro e quarto cachos, colhidos no estádio breaker (frutos verde claro com o primeiro surgimento de mancha rosa, vermelha ou amarela cobrindo até $10 \%$ de sua superfície), foram armazenados em condições ambientais (temperatura de $21^{\circ} \mathrm{C} \pm 2^{\circ} \mathrm{C}$ e umidade relativa de $50 \%+5 \%$ ) e analisados de acordo com o estádio de amadurecimento (breaker, rosa, vermelho-claro e vermelho), segundo Estados Unidos (1976) 
A textura foi determinada com o auxílio de penetrômetro Mc-Cormick com ponta de 7,94 mm de diâmetro. As medidas foram realizadas após remoção criteriosa da casca na região equatorial do fruto. Foram feitas três leituras por fruto, em $1 b f$, evitando-se as paredes radiais, por visualização das linhas que saem da região apical. Os resultados foram expressos em N, considerando-se $1 \mathrm{~N}=4,4483 \mathrm{lbf}$.

As substâncias pécticas foram extraídas segundo técnica descrita por McCready \& McComb (1952) e os teores de pectina total e solúvel determinados colorimetricamente segundo Bitter \& Muir (1962). Os resultados foram expressos em mg de pectina por $100 \mathrm{~g}$ de polpa. A porcentagem de solubilização foi obtida pela seguinte equação: (pectina solúvel/pectina total) x 100

A extração enzimática foi realizada segundo técnica de Buescher \& Furmanski (1978), com modificações. O tecido pericárpico foi triturado em liquidificador com água destilada resfriada (temperatura menor que $4^{\circ} \mathrm{C}$ ). $\mathrm{O}$ homogenato foi filtrado em tecido fino (organza), e o resíduo, ressuspendido em $\mathrm{NaCl} 1 \mathrm{M}$ resfriado. $\mathrm{O} \mathrm{pH}$ foi ajustado para 6,0 com $\mathrm{NaOH}$, e o novo homogenato foi incubado a $4^{\circ} \mathrm{C}$ por uma hora. Nova filtragem, em gaze, foi realizada, sendo o filtrado centrifugado a $5.000 \mathrm{~g}$, por 30 minutos, a $4^{\circ} \mathrm{C}$. O sobrenadante resultante foi, então, filtrado em papel-de-filtro, e o novo filtrado, utilizado para determinação de atividade enzimática

A atividade de pectinametilesterase (PME) foi determinada segundo Hultin et al. (1966) e Ratner et al. (1969). Um mililitro do extrato enzimático foi adicionado sobre $30 \mathrm{~mL}$ de pectina cítrica $1 \%$ em $\mathrm{NaCl} 0,1 \mathrm{M}$. O pH da solução foi mantido em torno de 7,0, por dez minutos, com $\mathrm{NaOH} 0,025 \mathrm{~N}$. Uma unidade de PME foi definida como a quantidade de enzima capaz de catalisar a desmetilação de pectina correspondente ao consumo de $1 \mu \mathrm{mol} \mathrm{de} \mathrm{NaOH}$ min $^{-1} \mathrm{~g}^{-1}$ de massa fresca, nas condições de ensaio.

A atividade de poligalacturonase (PG) foi determinada segundo Markovic et al. (1975). O extrato foi incubado em solução a $0,25 \%$ de ácido galacturônico (lavado com etanol $80 \%$ antes do uso) em tampão acetato de sódio $37,5 \mathrm{mM} \mathrm{pH} 5,0$ por três horas. A reação foi interrompida em banho-maria fervente, e os grupos redutores liberados determinados pela técnica de Somogyi, modificada por Nelson (1944), usando glicose como padrão. Como branco foi usado extrato inativado termicamente e incubado nas mesmas condições. Uma unidade de atividade de poligalacturonase foi considerada como a quantidade de enzima capaz de catalisar a formação de um nmol de grupos redutores por minuto nas condições do ensaio. Os resultados foram expressos em unidades por grama de peso fresco.
O experimento foi realizado em delineamento em blocos casualizados, com quatro repetições, sendo os tratamentos dispostos em esquema fatorial $2 \times 3 \times 4$, correspondente a dois status [normal $(+/+)$ e heterozigoto alcobaça $(+/ a l c)$ ], três backgrounds (Stevens, Piedmont e NC-8276) e quatro estádios de amadurecimento (breaker, rosa, vermelho-claro e vermelho). Cada parcela experimental consistiu de oito frutos, obtidos a partir de estandes de 30 plantas. Os resultados foram submetidos à análise de variância, e as respectivas médias foram comparadas pelo teste de Tukey a $5 \%$ de probabilidade.

\section{RESULTADOS E DISCUSSÃO}

A textura dos tomates foi influenciada pelo fator estádio de amadurecimento dos frutos, embora não tenha sido verificado efeito do alelo alcobaça ou efeitos interativos entre os fatores $(p<0,05)$. Verificou-se uma queda considerável na textura dos frutos à medida que eles amadureciam (Fig. 1). Um amaciamento acentuado durante $o$ amadurecimento de tomates normais e alcobaça também foi observado por Filgueiras (1996). Segundo Brummell \& Labavitch (1997), a firmeza de tomates reduz-se tipicamente com o amadurecimento. Ela constitui um importante critério para determinação de tomates frescos, visto que se associa a uma boa qualidade culinária e vida pós-colheita longa (Wann, 1996).

O teor de pectina solúvel foi influenciado pelos fatores status e estádio de amadurecimento, enquanto o teor de pectina total, apenas pelo fator estádio de

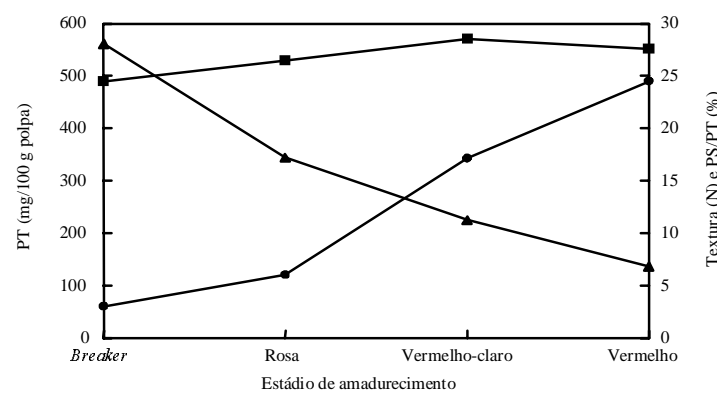

FIG. 1. Representação gráfica do comportamento de

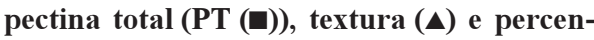
tagem de solubilização (PS/PT (•)) de tomates, em função dos estádio de amadurecimento (média entre tomates normais $(+/+)$ e alcobaça heterozigotos $(+/ a l c))$.

Pesq. agropec. bras., Brasília, v.35, n.7, p.1447-1453, jul. 2000 
amadurecimento $(\mathrm{p}<0,05)$. Os frutos alcobaça heterozigotos apresentaram, em média, menor teor de pectina solúvel (Fig. 2). Observou-se um aumento marcante no teor de pectina solúvel, visível, principalmente a partir do estádio de amadurecimento vermelho-claro. Os frutos breaker apresentaram um teor de pectina total inferior aos demais. Pôde-se observar uma tendência de síntese de pectinas do estádio breaker ao vermelho-claro com posterior tendência a degradação (Fig. 1). Analisando-se a porcentagem de solubilização das substâncias pécticas, pôde-se observar que os híbridos alcobaça heterozigotos apresentaram menor tendência de solubilização (Fig. 2), e que a porcentagem de solubilização aumentou à medida que os frutos amadureceram (Fig. 1). Resultados semelhantes quanto à porcentagem de solubilização foram observados por Filgueiras (1996) ao comparar tomates TOM-559 (alc/alc) com Flora Dade. O aumento na solubilização das substâncias pécticas se associou perfeitamente com a redução da textura observada durante 0 amadurecimento dos frutos (Fig. 1) à semelhança de resultados apresentados por outros autores (Resende, 1995; Filgueiras, 1996).

A atividade de PME foi influenciada apenas pelo fator status, não sendo observadas variações significativas durante o amadurecimento dos frutos $(\mathrm{p}<0,05)$. Os híbridos alcobaça apresentaram, em mé-

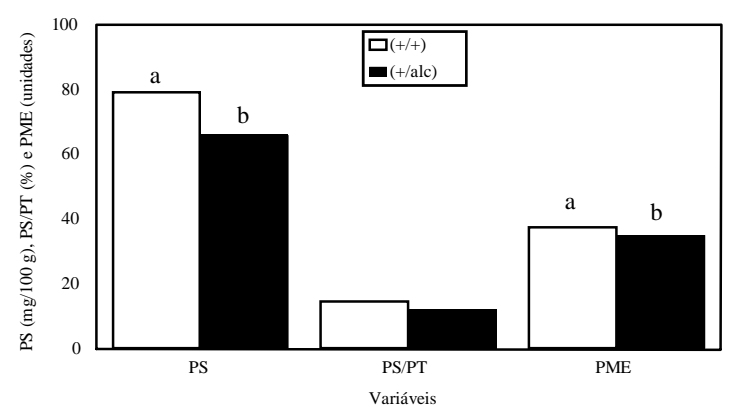

FIG. 2. Representação gráfica dos teores médios de pectina solúvel (PS), porcentagem de solubilização (PS/PT) e atividade de pectinametilesterase (PME) de tomates normais $(+/+)$ e alcobaça heterozigotos $(+/ a l c)$ (letras diferentes, em cada par de barras, representam diferenças significativas pelo teste de Tukey a $\mathbf{p}<0,05)$.

Pesq. agropec. bras., Brasília, v.35, n.7, p.1447-1453, jul. 2000 dia, menor atividade da referida enzima (Fig. 2). Segundo Koch \& Nevins (1989), a atividade da PME é inicialmente detectada no pericarpo de tomates no estádio breaker, com a desesterificação péctica ocorrendo na passagem desse estádio para o rosa. De acordo com Harriman et al. (1991) e Resende (1995), um aumento na atividade da PME do estádio verdematuro para o breaker foi observado, e que a atividade da enzima voltou a níveis normais logo em seguida.

A PME não apresentou, em média, oscilações significativas durante o amadurecimento dos híbridos estudados (Fig. 3), provavelmente porque já havia atingido o seu pico de atividade, tendo-se em vista a colheita dos frutos já no estádio breaker de amadurecimento. Variações na atividade de PME durante 0 amadurecimento de diferentes genótipos de tomate com picos de atividade atingidos em distintos estádios de amadurecimento também têm sido observadas (Filgueiras, 1996).

A atividade da enzima PG foi afetada tanto pela interação entre status e background como pela interação entre status e estádio de amadurecimento $(\mathrm{p}<0,05)$. Os frutos alcobaça heterozigotos apresentaram, em média, menor atividade de PG, em comparação com os normais, nos estádios rosa, vermelhoclaro e vermelho, enquanto no estádio breaker nenhuma diferença foi notada (Fig. 4). Esta menor atividade de PG não foi suficiente para diminuir a perda

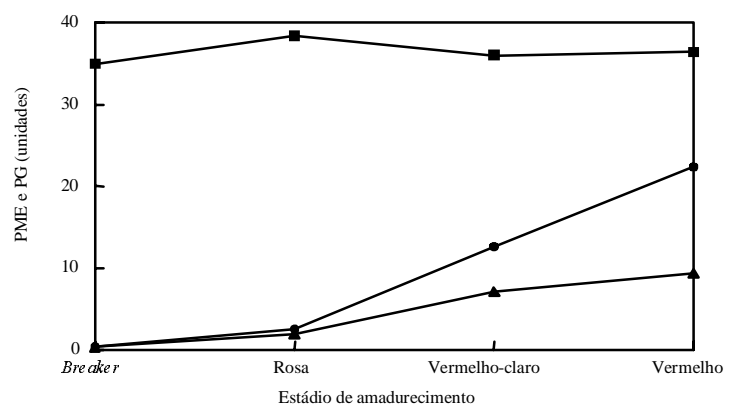

FIG. 3. Representação gráfica da atividade enzimática média de pectinametilesterase (PME (ם)) e poligalacturonase (PG) de tomates normais $(+/+)(\bullet)$ e alcobaça heterozigotos $(+/$ alc $)(\Delta)$, em função do estádio de amadurecimento. 
de firmeza, nos estádios de amadurecimento estudados. Todavia, deve-se considerar que os frutos alcobaça apresentaram uma vida pós-colheita superior à dos normais, e que a menor atividade da $\mathrm{PG}$ pode ter contribuído para uma contenção da firmeza durante esse processo. Não obstante, a baixa atividade da PG se relaciona com a menor porcentagem da solubilização das substâncias pécticas notada nos tomates alcobaça. Ao contrário dos resultados obtidos, uma relação inversa tem sido observada entre a retenção da firmeza e atividade de $\mathrm{PG}$, suportada por estudos com tomates transgênicos, mutantes alcobaça, nor e rin, em homozigose e heterozigose, e híbridos normais. $\mathrm{O}$ amadurecimento e amaciamento são retardados nos mutantes, que desenvolvem menor atividade de PG (Buescher et al., 1976; Kopeliovitch et al., 1980; Brummell \& Labavitch, 1997).

O alelo alcobaça determinou menor atividade de PG nos híbridos com background Stevens e NC-8276, embora sua influência não tenha sido detectada sobre híbridos com background Piedmont (Fig. 5). Segundo Hobson \& Grierson (1993), o alelo alcobaça afeta consideravelmente o amadurecimento de tomates, reduzindo a atividade da PG, embora a resposta seja variável em função do background.

A atividade da PG aumentou, tanto nos híbridos alcobaça heterozigotos quanto nos normais, com o amadurecimento (Fig. 3). Esse aumento na atividade

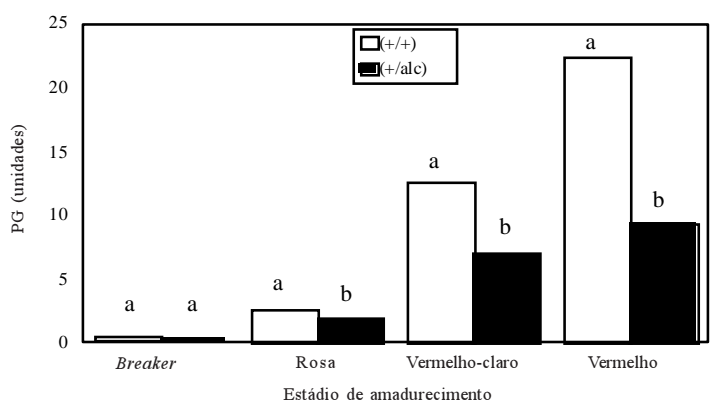

FIG. 4. Representação gráfica da atividade enzimática de poligalacturonase (PG) em função dos estádios de amadurecimento de tomates normais $(+/+)$ e alcobaça heterozigotos $(+/ a l c)$ (letras diferentes, em cada par de barras, representam diferenças significativas pelo teste de Tukey a $\mathbf{p}<0,05$ ). da PG acompanhou a solubilização das substâncias pécticas e redução da firmeza, como o ilustrado na Fig. 1. Filgueiras (1996) constatou, à semelhança do observado no presente trabalho, um incremento na atividade da PG durante o amadurecimento, na planta, de tomates de amadurecimento normal, homozigotos alcobaça e seus híbridos heterozigotos.

O alelo alcobaça em heterozigose foi eficaz na supressão parcial das atividades das enzimas PME e PG e solubilização das substâncias pécticas, um dos mais importantes mecanismos de amaciamento de tomates, embora não tenha influenciado a textura dos frutos nos estádios de amadurecimento breaker, rosa, vermelho-claro e vermelho. Entretanto, há que se salientar que o alelo alcobaça em heterozigose determinou um retardo de cerca de dois dias na evolução do processo de amadurecimento dos frutos armazenados à temperatura ambiente entre os estádios breaker e vermelho. Logo, o efeito alcobaça poderia ter se mostrado evidente sobre a variável textura se ao invés de ter-se optado pelas avaliações em função do estádio de amadurecimento, baseado na coloração da casca, tivesse se optado pelas avaliações em função do tempo. Embora se tenha verificado uma associação entre a atividade da $\mathrm{PG}$, solubilização de substâncias pécticas e amaciamento do fruto, uma complexa ação enzimática coordenada é cogitada no amadurecimento do tomate.

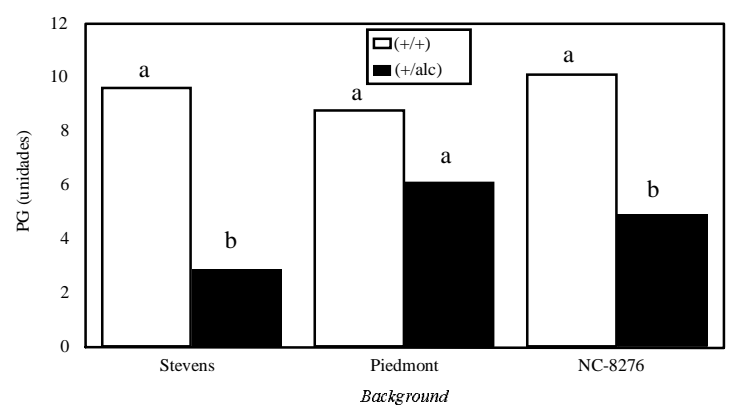

FIG. 5. Representação gráfica da atividade enzimática de poligalacturonase (PG), em função de três backgrounds distintos, de tomates normais $(+/+)$ e alcobaça heterozigotos (+/alc) (letras diferentes, em cada par de barras, representam diferenças significativas pelo teste Tukey a $\mathrm{p}<0,05$ ).

Pesq. agropec. bras., Brasília, v.35, n.7, p.1447-1453, jul. 2000 


\section{CONCLUSÕES}

1. A textura de tomates, em estádios predeterminados de amadurecimento baseados na coloração da casca, não é influenciada pelo alelo alcobaça em heterozigose.

2. O alelo alcobaça em heterozigose reduz a atividade das enzimas pectinametilesterase e poligalacturonase e a percentagem de solubilização de substâncias pécticas na polpa dos tomates.

3. O amadurecimento pós-colheita de tomates alcobaça heterozigotos, a partir do estádio breaker, é marcado pelo seu amaciamento, que é acompanhado por elevação da atividade da enzima poligalacturonase e pela solubilização das substância pécticas.

4. O melhoramento genético do tomate visando a sua conservação pós-colheita, a partir da manipulação do loco alcobaça, apresenta-se com grande potencial de utilização.

\section{REFERÊNCIAS}

ARAÚJO, M.L. de. Interações intra-loco e inter-locus alcobaça, crimsom e hight pigment sobre características de qualidade e de produção de frutos do tomateiro. Lavras : UFLA, 1997. 131p. Tese de Doutorado.

BITTER, T.; MUIR, H.M. A modified uronic acid carbazole reaction. Analytical Biochemistry, San Diego, v.34, p.330-334, 1962.

BRUMMELL, D.A.; LABAVITCH, J.M. Effect of antisense suppression of endopolygalacturonase activity on polyuronid molecular weight in ripening tomato fruit and in fruit homogenates. Plant Physiology, Rockville, v.115, n.2, p.715-725, Oct. 1997.

BUESCHER, R.W.; FURMANSKI, R.J. Role of the pectinesterase and polygalacturonase in the formation of woolliness in peaches. Journal of Food Science, Chicago, v.43, n.1, p.264-266, Jan./ Feb. 1978

BUESCHER, R.W.; SISTRUNK, W.A.; TIGCHELAAR, E.C.; NG, T.J. Softening, pectolytic activity and storage-life of rin and nor tomato hybrids HortScience, Alexandria, v.11, n.6, p.603-604, Dec. 1976.

Pesq. agropec. bras., Brasília, v.35, n.7, p.1447-1453, jul. 2000
CARPITA, N.C.; GIBEAUT, D.M. Structural models of primary cell walls in flowering plants: consistency of molecular structure with the physical properties of the walls during growth. Plant Journal, Oxford, v.3, p.1-30, 1993.

ESTADOS UNIDOS. Department of Agriculture. United States standards for grades of fresh tomatoes Washington : USDA-Agriculture Marketing Service, 1976. $10 \mathrm{p}$

FILGUEIRAS, H.A.C. Bioquímica do amadurecimento de tomates híbridos heterozigotos no loco "alcobaça". Lavras: UFLA, 1996. 118p. Tese de Doutorado.

FREITAS, J.A. de. Produtividade e qualidade de frutos de híbridos de tomateiro, heterozigotos no loco alcobaça. Lavras : UFLA, 1996. 86p. Dissertação de Mestrado.

GAFFE, J.; TIZNADO, M.E.; HANDA, A.K. Characterization and functional expression of an ubiquitously expressed tomato pectin methylesterase. Plant Physiology, Rockville, v.114, n.4, p.1547-1556, Aug. 1997

GROSS, K.C.; WALLNER, S.J. Degradation of cell wall polysaccharides during tomato fruit ripening. Plant Physiology, Rockville, v.63, n.1, p.117-120, Jan 1979

HARRIMAN, R.W.; TIEMAN, D.M.; HANDA, A.K Molecular cloning of tomatos pectin methylesterase gene and its expression in rutgers, ripening inhibitor, non ripening, and never ripe tomatos fruits. Plant Physiology, Rockville, v.97, n.1, p.80-87, Sept. 1991.

HOBSON, G.E.; GRIERSON, D. Tomato. In: SEYMOUR, G.B.; TAYLOR, J.E.; TUCKER, G.A (Ed.). Biochemistry of fruit ripening. London : Chapman \& Hall, 1993. p.405-442.

HUBER, D.J. Polyuronide degradation and hemicellulose modifications in ripening tomato fruit. American Society for Horticultural Science Journal, Alexandria, v.108, n.3, p.405-409, May 1983

HULTIN, H.O.; SAM, B.; BULGER, J. Pectin methyl esterase of the banana: purification and properties. Journal of Food Science, Chicago, v.31, n.3, p.320327, May/June 1966.

HUYSAMER, M.; GREVE, L.C.; LABAVITCH, J.M. Cell wall metabolism in ripening fruit. VIII. Cell wall composition and synthetic capacity of two regions of the outer pericarp of mature green and red ripe cv. 
Jackpot tomatoes. Physiologia Plantarum, Copenhagen, v.101, n.2, p.314-322, Oct. 1997a.

HUYSAMER, M.; GREVE, L.C.; LABAVITCH, J.M Cell wall metabolism in ripening fruit. IX. Synthesis of pectic and hemicellulosic cell wall polymers in the outer pericarp of mature green tomatoes (cv. XMT-22). Plant Physiology, Rockville, v.114, n.4, p.1523-1531, Aug. 1997b

KOCH, J.L.; NEVINS, D.J. Tomato fruit cell wall. I. Use of purified tomato polygalacturonase and pectinmethylesterase to identify development changes in pectins. Plant Physiology, Rockville, v.91, n.3, p.816-822, Nov. 1989

KOPELIOVITCH, E.; MIZRAHI, Y.; RABINOWITCH, H.D.; KEDAR, N. Physiology of the tomato mutant "alcobaca". Physiologia Plantarum, Copenhagen, v.48, n.3, p.307-311, Mar. 1980

LAZAN, H.; ALI, Z.M. Cell wall hydrolases and their potential in the manipulation of ripening of tropical fruits. ASEAN Food Journal, New York, v.8, n.2, p.47-53, 1993

LELIÈVRE, J.M.; LATCHÉ, A.; JONES, B.; BOUZAYEN, M.; PECH, J.C. Ethylene and fruit ripening. Physiologia Plantarum, Copenhagen, v.101, n.4, p.727-739, Dec. 1997.

McCREADY, P.M.; McCOMB, E.A. Extraction and determination of total pectic material. Analytical Chemistry, Washington, v.24, n.12, p.1586-1588, Dec. 1952

MARKOVIC, O; HEIRICHVÁ, K.; LENKEY, B. Pectolytic enzymes from banana. Collection of
Czechoslovak Chemistry Communications, Prague, v.40, p.769-774, 1975.

MUTSCHLER, M.A. Inheritance and linkage of the "alcobaca" ripening mutant in tomato. American Society for Horticultural Science Journal, Alexandria, v.109, n.4, p.500-503, July 1984

NELSON, N.A. A photometric adaptation of Somogyi method for the determination of glucose. Journal of Biological Chemistry, Bethesda, v.135, p.136-175, 1944.

RATNER, A.; GOREN, R.; MONSELINE, S.P. Activity of pectin esterase and cellulase in the abscission zone of citrus leaf explants. Plant Physiology, Rockville, v.44, n.12, p.1717-1723, Dec. 1969

RESENDE, J.M. Qualidade pós-colheita de dez genótipos de tomate do grupo multilocular. Lavras : UFLA, 1995. 90p. Dissertação de Mestrado.

SOUZA, J.C. de. Avaliação de tomateiros híbridos, do grupo multilocular, portadores do alelo alcobaça em heterozigose. Lavras : UFLA, 1995. 56p. Dissertação de Mestrado.

STEELE, N.A.; McCANN, M.C.; ROBERTS, K. Pectin modification in cell walls of ripening tomatoes occurs in distinct domains. Plant Physiology, Rockville, v.114, n.1, p.373-381, May 1997.

WANN, E.V. Physical characteristics of mature green and ripe tomato fruit tissue of normal and firm genotypes. American Society for Horticultural Science Journal, Alexandria, v.121, n.3, p.380-383, May 1996 